cataract surgery in the same hands. Rehabilitation is much easier than with other methods. The postoperative vision and orientation seem natural, and the patient can often see well without an additional optical correction. With this technique cataract surgery can be offered to patients with unilateral lens opacities which used to be left untreated when the fellow eye remained unaffected.

Provided, therefore, that preoperative assessment excludes the presence of other conditions affecting the eye and any general disease which would have an adverse influence, the prospects for cataract surgery are good. In uncomplicated cases over $95 \%$ of patients may expect to achieve a final corrected vision of $6 / 12$ or better.

M J ROPER-HALL

Consultant Ophthalmologist,

Birmingham B15 3HE

1 Roper-Hall MJ, ed. Stallard's eye surgery. 6th ed. Bristol: Wright, 1980.

${ }^{2}$ Ruben M, Choyce DP, Roper-Hall MJ, et al. Symposium on the correction of aphakia. Trans Ophthalmol Soc UK 1981;101:48-86.

\section{Do alcoholics recover?}

Doctors weary of exhortations to identify alcoholics, and many resent the suggestion that they should be treating them, too. Do not alcoholics inevitably slide downhill, perhaps with brief plateaux, with few if any recovering? This stereotype might, however, be based only on a few recalcitrant and unrepresentative bad pennies. Doctors seldom meet recovered alcoholics in their clinics or surgeries. What are the prospects for recovery? And how much difference is made by medical intervention?

A series of surveys in the United States, with follow-ups after two to three years, have shown that people move into and out of problem drinking. ${ }^{12}$ Two-thirds have improved by the second interview and half are free of problems. Even if follow-up is complete (which is only sometimes the case ${ }^{1}$ ) such surveys may be criticised. Possibly they may not detect "real" alcoholics in the first place: they may miss homeless individuals and people who are never in when the interviewer calls. Perhaps, moreover, "real" alcoholics go undetected because they lie.

Neither these two criticisms nor the pitfall of loss to follow-up applied to two recently reported longer-term studies, both of defined populations. The Lundby cohort consisted of all adults living in a Swedish town on 1 July 1947. In 1957 all were reinterviewed by a psychiatrist, and 96 of the 1312 men were classified as alcoholics. They were interviewed again 15 years later, and information from official sources, families, and neighbours collated. ${ }^{3}$ Of the 96 alcoholics, 29 had recovered, 42 were unchanged or worse, and 25 had died (though only four of them died below the age of 65).

Vaillant and Milofsky have used data on inner-city teenagers originally studied in the 1940 s and reinterviewed at ages 25 , 31 , and $47 .^{4}$ Arrest and clinic records were obtained. The criteria for alcohol abuse at some point in their lives had been fulfilled in 110 men. By the age of 47 some 35 of these 110 men continued to abuse alcohol and could be termed progressive alcoholics. Nevertheless, 38 were abstinent and 21 of them had achieved at least three years of abstinence (average 10 years); 26 were still drinking, but without any problems in the preceding 12 months, and 18 of these had achieved two or more years of asymptomatic drinking (average 10 years).

Recovery rates reported from clinics are similar or slightly $\frac{3}{2}$ worse, with $20-40 \%$ of patients doing well and another third 은 somewhat improved. ${ }^{5-7}$ Though on average they are probably $\overparen{\Omega}$ not "severer" alcoholics than those found in community $\overline{\bar{J}}$ studies, clinic patients might include a higher proportion of $D_{0}$ socially dislocated people. Perhaps, too, clinics may attract $\$$ patients with tendencies to depression or passivity, which $\stackrel{0}{0}$ might augur for a bad prognosis. Moreover, people who seek help or are coerced to attend a clinic are likely to be those who have already failed to "cure" themselves or who are reluctant 0 to try.

Treatment may actually make some alcoholics worse, by $\frac{\bar{\omega}}{\widehat{\phi}}$ sheltering them from the consequences of their drinking or $\varnothing$ fostering passivity. The gauntlet has been thrown down ${ }^{8}$ : क the onus of proof is now on therapists who try to provide $\overrightarrow{0}$ more than just succour to show that they are necessary agents $\vec{\overrightarrow{ }}$ in the recovery of certain of their patients and to show which $\stackrel{\omega}{\sigma}$ these are.

Recovery of alcoholics detected in community studies is sometimes but not often attributable to treatment. ${ }^{134}$ Both ơ in clinics and in surveys the best predictor is stability in one's job and marriage..$^{359}$ While important in the Lundby study, severity, in terms of degree of dependence and number of $\dot{\omega}$ symptoms, did not emerge as an important factor in Vaillant's 은 data. The link between good outcome and social stability is $\omega$ sometimes thought to be attributable to personality: secure, conscientious people who choose their job and spouse wisely also tackle their drinking problem seriously. Knupfer found that good outcome was commoner in those who reported a ? stable childhood, but this was a retrospective assessment. ${ }^{1}$ Vaillant, who had data uncontaminated by the patient's memory, did not find a link between childhood disturbance and poor outcome. Sociopathy did not predict outcome in either of these community-based studies.

All these follow-up studies (and many others ${ }^{10}$ ) have found alcoholics who have gone on to live healthy stable lives yet have continued to drink. Those who achieve this result are usually younger and have experienced fewer symptoms than average. Probably abstinence is seriously attempted only by those whose distress is so severe that a radical solution seems commensurate; or individuals who are conscientious, can organise their lives, and have self-control may not let $\dot{\delta}$ their drinking get too bad before they do something about it. ₹ They then successfully apply those traits to changing their $\frac{\text { o }}{2}$ pattern of living in such a way that their drinking is never to $N$ excess. But it is also possible that a physiological factor $\rightarrow$ contributes-less severely dependent drinkers might be less prone to reinstate the vicious circle of withdrawal symptoms and relief drinking which leads to relapse in those who are $N$ severely dependent.

The route by which individuals "spontaneously" recover is obviously of interest to the beleaguered clinician. Change of job; a new relationship; criticism from family or friends; a $\stackrel{?}{+}$ disturbing illness-these are some of the more commonly mentioned factors. ${ }^{1112}$ Some describe finding a substitute: tranquillisers, eating, meditation, work, hobbies. Of Vaillant's securely abstinent men, a third had used Alcoholics Anonymous. Clearly, however, many individuals recover without incorporating into their view of themselves that "I am an alcoholic."112 Fresh hope and new self-esteem were important elements in the recovery of the men in Vaillant's study. Our understanding of alcoholism will be restricted if 
we study only those who attend clinics or if we use too short a span of time. There is much to learn from studying natural healing processes.

Jonathan Chick

Consultant Psychiatrist,

Royal Edinburgh Hospital,

Edinburgh EH10 5HF

${ }^{1}$ Knupfer G. Ex-problem drinkers. In: Roff M, Robins L, Pollack H, eds. Life history research in psychopathology. Vol 2. Minneapolis: University Life history research in psychopatholo

2 Clark WB, Cahalan D. Changes in problem drinking over a four-year span. Addictive Behaviours 1976;1:251-9.

3 Ojesjö L. Long-term outcome in alcohol abuse and alcoholism among males in the Lundby general population, Sweden. Br $\mathcal{F}$ Addict 1981; 76:391-400.

4 Vaillant GE, Milofsky ES. Natural history of male alcoholism. IV. Paths to recovery. Arch Gen Psychiatry 1982;39:127-33.

6 Vaillant GE. The doctor's dilemma. In: Edwards G, Grant M, eds. Alcoholism treatment in transition. London: Croom Helm, 1980:13-31.

- Emrick CD. A review of psychologically oriented treatment of alcoholism. 1. The use and interrelationships of outcome criteria and drinking behaviour following treatment. Quarterly fournal of Studies on Alcohol 1974 ;35A :523-49.

${ }^{7}$ Polich JM, Armor DJ, Braiker HB. The course of alcoholism: four years after treatment. Santa Monica, California: Rand Corporation, 1979.

8 Orford J, Edwards G. Alcoholism. London: Oxford University Press, 1977.

9 Costello RM. Alcoholism treatment and evaluation: slicing the outcome variance pie. In: Edwards G, Grant M, eds. Alcoholism treatment in transition. London: Croom Helm, 1980:113-27.

10 Heather N, Robertson I. Controlled drinking. London: Methuen, 1981.

11 Saunders WM, Kershaw PV. Spontaneous remission from alcoholisma community study. $B r \mathcal{F}$ Addict 1979;79:251-65.

12 Tuchfeld BS. Spontaneous remission in alcoholics. Empirical observations and theoretical implications. $\mathcal{f}$ Stud Alcohol $1981 ; 42: 626-41$.

\section{Headache and tumours in children}

Headaches, the epilepsies, and various neurodevelopmental and learning disorders account for most of the neurological problems seen by general practitioners which may require referral to a paediatric neurologist. The recent onset of symptoms and a progressive course distinguish conditions such as cerebral tumours, hydrocephalus, and neurodegenerative diseases from the relatively unchanging disorders which are grouped under the rubric of cerebral palsy.

Cerebral tumours are the second most common group of cancers in childhood after the leukaemias and they are usually highly invasive and rapidly progressive-two facts that cause considerable anxiety to those responsible for the early diagnosis of these life-threatening conditions. Furthermore, until the advent of computed tomography scanning the risks and discomforts of the invasive diagnostic methods required for diagnosis, such as pneumoencephalography and arteriography, made complete investigation difficult and hazardous.

Yet, despite the technological advances of the past decade, clinical evaluation must remain the cornerstone of diagnosis, so that an accurate and detailed history is of paramount importance. Parents associate brain tumours with headaches and vice versa, and probably most doctors would also nominate headache as the leading symptom of a cerebral neoplasm. In fact, most children with severe headaches have migraine, ${ }^{1}$ but its features of periodicity, throbbing, and associated nausea and vomiting are symptoms that may also characterise headache due to a space-occupying lesion. An important difference may be the presence of a family history, so often found in patients with migraine.
In a recent report from the United States, Honig and Charney ${ }^{2}$ have tried to devise a set of clinical clues which might raise the level of suspicion of tumour and make further investigation mandatory. They analysed the clinical data and skull radiographs from 105 children with a final diagnosis of brain tumour for the period 1965-78. A third of the children were aged between 1 and 5 years and three-quarters were aged 10 or less. Headaches were a symptom in 72 of the 105 children. The headaches were often similar to those due to more benign causes, but the authors emphasised the importance of recurrent morning headaches, headaches awakening the child from sleep, intense prolonged incapacitating headaches, and changes in the quality, frequency, and pattern of headaches as historical indications for further investigation. Almost one-third of all the children were awakened from sleep by headache or complained of headache after getting up in the morning. Vomiting was associated with headache in nearly $80 \%$ of those with the complaint and often increased in frequency coincidentally with increasing frequency or severity of the headache.

Of the 72 children with headache as a symptom, 68 had neurological or ocular signs or both at the time of diagnosis. Some 49 had ataxia, 18 had head tilt, and 63 had papilloedema. The abnormal signs developed two weeks after the headache in 33 children, within eight weeks in 51 , and by 24 weeks in the remainder of the 68 . In some of the patients in whom the appearance of abnormal signs was delayed the eventual diagnosis was craniopharyngioma, and other clinical clues included short stature or the development of polydipsia and polyuria.

These findings show very clearly the crucial importance of careful clinical examination in all children with headaches of recent onset, since neurological or ocular abnormalities may be expected to occur relatively early in the illness when an expanding lesion is present. The eyes should be examined for changes in pupil size, the presence of strabismus, fundal changes, impairment of the visual field, and visual acuity. The last named may present problems because children do not readily perceive visual changes, and vision may become seriously impaired before it is first noted by the child. ${ }^{3}$ The late Mary Sheridan made an important contribution ${ }^{4}$ to testing visual acuity in the young, and her methods should be used more widely. Examination of the skin for pigmentation is also important; headaches were associated with neurofibromatosis in three patients in the American series. A glioma of the optic nerve or chiasma is the usual intraorbital or intracranial lesion present with neurofibromatosis, and unilateral or bilateral blindness or a visual-field defect may occur.

Skull $x$-ray films were available for 56 of the 72 patients with headaches; just over half of these showed abnormalities. The usual abnormal finding was separation of the sutures, but calcification was present in nine of 30 positive cases, presumably as a consequence of the unusually large number of craniopharyngiomas (14) in the total series. ${ }^{5}$ The conclusion drawn is that screening by skull radiography is of questionable value, since 26 of the 56 children had normal $x$-ray appearances at the time of diagnosis.

A child with a recent onset of headaches should therefore be observed very closely during the first two months after the headaches start, because neurological and ocular abnormalities develop most frequently during that period. A headache which changes in character, increases in frequency and severity, and which is associated with awakening and with vomiting is especially suspicious. In a commentary on the American article, Barlow ${ }^{6}$ emphasises the importance of behavioural 